\title{
The role of hazardous factors of chemical and physical nature in welders' occupational risks management
}

\author{
Yuriy Bulygin ${ }^{1 *}$, Elena Andreeva ${ }^{1}$, and David Shoniya ${ }^{1}$ \\ ${ }^{1}$ Don State Technical University, Rostov-on-Don, Gagarin sq., 1, 344003, Russia
}

\begin{abstract}
The article is devoted to a review of the available scientific approaches to assess the role of hazardous factors of physical and chemical nature, which are very important for the management of occupational risks of workers in dust-hazardous industries using the example of welders. General approaches and models for assessing the risk to public health in general are presented quite fully, the mechanisms of the effect of dust particles on the development of occupational pathologies in welders, including toxic and carcinogenic ones, have been studied in depth, a number of articles are devoted to the study of the effect of a thermal (physical) factor of a chronic nature. The above studies are of a scattered nature, the combined effect of physical and chemical factors are not taken into account, based on the S. Arrhenius equation, which is especially important in the closed spaces of the working area. There is no comprehensive methodology for assessing health risks for workers in dusthazardous industries and welders. The development of the abovementioned comprehensive methodology for assessing health risk of workers in dust-hazardous industries based on taking into account hazardous factors of physical and chemical nature is very promising in the near future.
\end{abstract}

\section{Introduction}

In the working process the welder is been a subject of various harmful and dangerous factors which affect his performance and health (Fig. 1). These factors are actually combined by complex direct and feedback links and have a complex effect. However, sanitary and hygienic elements that determine the working conditions at the workplace have the dominant effect on the welder. Let us consider in more detail the factors of physical and chemical nature that determine the methodological approaches to welders' occupational risks management.

The arc welding process is accompanied by the release of a welding aerosol into the air of the welder's working area. Welding aerosol is a mixture of gases and fine dust, which causes its easy penetration through the respiratory system into the welder's body. Most of the elements of welding aerosol are toxic substances of I and II hazard classes. The effect of welding aerosol on welder's health, types and nature of occupational diseases of welders

*Corresponding author: bulyur_rostov@mail.ru 
have been studied quite fully and are considered in detail in the works of K.V. Migaya, L.N. Gorbonya, A.P. Golovotyuka, R.M. Stern [1]. It has been established that the nature of the development and the complication of the course of occupational diseases depends on the chemical composition, concentration and duration of exposure to the welding aerosol.

The mechanism of formation and the nature of the welding aerosol emission during arc welding is described in detail in works of I.K. Pokhodnya, K.A. Yushchenko, I.R. Yavdoshina, A.V. Bulat, V.N. Gorpenyuk, V.G. Voitkevich, O.G. Levchenko, V.M. Grishagin, M. Kobayashi, N. Jenkins, J. Moreton, N. Morita, R.F. Heile, D.C. Hill dating back to the 1970s [2].

V.M. Grishagin considers the mechanism of formation of welding aerosol to be condensation aerosols, and the composition of the welding aerosol is a dispersed system in which fine particles of solid matter are the dispersed phase - solid constituent of welding aerosol, dispersed medium - gas mixture, or gaseous constituent of welding aerosol.

The study (M. Kobayashi, J. Moreton, N. Morita, V.G. Voitkevich) the structures of the welding aerosol formed during welding with coated electrodes and flux-cored wires and wires of solid cross-section in an atmosphere of carbon dioxide showed that they have a complex phase composition, and the same chemical element can be a part of several compounds [3]. For example, potassium is formed by the connections $\mathrm{K}_{2} \mathrm{CO}_{3}, \mathrm{KFeO}_{2}$, $\mathrm{KCaF}_{3}$, fluorine $-\mathrm{CaF}_{2}, \mathrm{NaF}, \mathrm{FeF}_{3}, \mathrm{MnF}_{2}$. This factor significantly complicates the modeling and prediction of the chemical composition of the welding aerosol. As indicated, the inhomogeneity of the phase composition of the welding aerosol particles is associated with the inhomogeneity of the temperature field of the steam and its individual components condense at different temperatures.

It is likely that in the light of this circumstance, the prediction of the composition of the welding aerosol in a closed space with a significant increase in heat as a result of the action of various types of heat transfer, i.e. within the framework of the scientific problem being solved in this project.

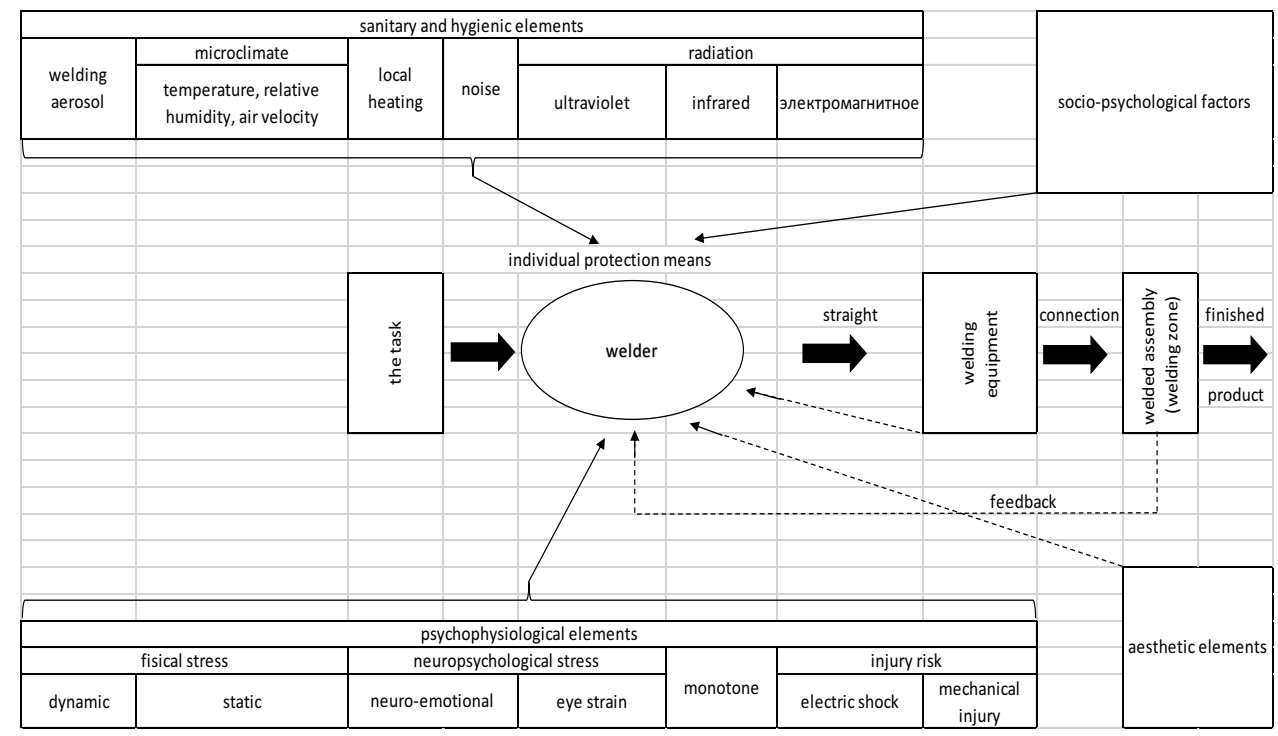

Fig. 1. Combination of factors of various natures acting on the welder.

M.I. Erman, A.G. Potapievsky, M. Kobayashi experimentally proved that the role of chemical composition of base metal in welding aerosol formation is insignificant due to the lower temperature of weld pool surface in comparison with the electrode end and the electrode metal drops, i.e. the main source of welding aerosol is the evaporation of metal 
from the end of the electrode and the surface of the droplets [4]. It can be argued that the research in this project for rimmed steel grades of pipes can be transferred to all steels of the same type from which main pipelines are made.

M. Kobayashi, N. Jenkins, I.K. Pokhodnya include the chemical composition of welding consumables and welded metals, shielding gases and technological parameters of welding modes into the factors that determine the chemical composition and the amount of emitted welding aerosol [5].

Generalization and systematization of numerous physicochemical studies carried out by V.M. Grishagin [5,15] showed, that the solid constituent of the welding aerosol (SCWA) formed during welding with coated electrodes includes base metals ( $\mathrm{Mn}, \mathrm{Fe}, \mathrm{Si}, \mathrm{K}, \mathrm{Na}, \mathrm{Ca}$, $\mathrm{Mg}, \mathrm{Ti}, \mathrm{Al}, \mathrm{Cr}, \mathrm{Ni}, \mathrm{F}$ ) and impurity metals (As, Cu, Rb, Sn, Zr, Sr, Nb, Mo, Ag, Sb, Ba, Pb), as well as complex mixtures of metals, simple and complex metal oxides and spinels $\mathrm{MnFe} 2 \mathrm{O} 4, \mathrm{CaFe}_{2} \mathrm{O} 4,(\mathrm{Fe}, \mathrm{Mn}) \mathrm{OFe}_{2} \mathrm{O}_{3}, \mathrm{~K}_{2} \mathrm{Cr}_{2} \mathrm{O}_{7}, \mathrm{Na}_{2} \mathrm{Cr}_{2} \mathrm{O}_{7}, \mathrm{Fe}_{3} \mathrm{O}_{4}$ and other fluorides (NaF, $\mathrm{KF}, \mathrm{K}_{3} \mathrm{FeF}_{6}, \mathrm{~K}_{2} \mathrm{SiF}_{6}, \mathrm{CaF}_{2}$ etc.), silicates $\left(\mathrm{CaSiO}_{3}\right.$, -Si-O-Si-O-Si-, $\mathrm{Fe}_{2}\left[\mathrm{SiO}_{4}\right], \mathrm{Mn}_{2}\left[\mathrm{SiO}_{4}\right]$ etc.). When performing work involving the use of calcium carbide, usually contaminated with calcium phosphide, phosphine is formed $\left(\mathrm{PH}_{3}\right)$. In case of welding (cutting) parts, assemblies, structures, materials covered with preservatives, paint and/or contamination of technological origin, hydrogen chloride can be released into the gas phase $(\mathrm{HCl})$, chlorine $\left(\mathrm{Cl}_{2}\right)$, phosgene $\left(\mathrm{COCl}_{2}\right)$, carbon tetrachloride $\left(\mathrm{CCl}_{4}\right)$, trichlorethylene $\left(\mathrm{CCl}_{2}=\mathrm{CHCl}\right)$, sulfurous and sulfuric anhydrides $\left(\mathrm{SO}_{2}, \mathrm{SO}_{3}\right)$, hydrogen sulfide $\left(\mathrm{H}_{2} \mathrm{~S}\right)$, phosphorus $\left(\mathrm{P}_{4}\right)$, phosphoric anhydride $\left(\mathrm{P}_{2} \mathrm{O}_{5}\right)$, phosphine $\left(\mathrm{PH}_{3}\right)$ and other toxic compounds. These data are obtained using complex and lengthy methods of analysis (X-ray, spectrophotometric, etc.), therefore, it is very important to be able to predict the working conditions of welders in confined spaces on the basis of creating a non-stationary mathematical model of heat and mass transfer.

In recent years, mathematical models have been intensively developed to determine the chemical composition and level of emission of welding aerosol (A.A. Buki, O.G. Levchenko, V.M. Grishagin), information and calculation systems for assessing the hygienic characteristics of welding electrodes (O.G. Levchenko, V.V. Savitsky, A.O. Lukyanenko). N.F. Tishchenko in the reference book "Protection of Atmospheric Air" provides a large amount of data on the specific emissions of harmful substances during welding and surfacing for various methods of welding and surfacing, grades of welding materials.

Thus, a review of the literature has shown that the processes of formation of a welding aerosol during arc welding have been sufficiently studied, however, there is absolutely no information on the chemical composition and nature of the emission of a welding aerosol during welding with self-shielded flux-cored wires Innershield NR-207, NR-208, and recommendations for reducing harmful emissions, in cases of limited space with a high rate of increase in heat, obviously far from perfect.

In addition to the mechanisms and models of the formation and release of welding aerosols and gases, a review of which is given above, it is necessary to consider in more detail the models of propagation (heat and mass transfer) of welding aerosols and gases.

\section{Results and Discussion}

The importance of using mathematical modeling in the study of harmful substances and heat spread processes, in conditions of active ventilation of premises, was noted in the works of Elterman V.M., Titov V.P., Kuvshinov Yu.Y., Grimitlin M.I., Polushkin V.I., Minko V.A., Kokorina O.Ya., Poza M.Ya., Logacheva I.N., Logacheva K.I., Talieva V.N., Datsyuka T.A., Polosina I.I. and etc. [4]. 
In these works, various approaches to the construction of mathematical models of ventilation processes are considered, based on the equations of motion, continuity of the medium, thermal conductivity and matter transfer. Mathematical modeling of the processes of heat and mass transfer of explosives and IT in rooms is associated with the consideration of three-dimensional objects with complex geometry, distributed systems for supplying and removing air through ventilation holes, placed equipment of complex shapes and sources of harmful substances.

Previously, the authors of this article considered a non-stationary three-dimensional mathematical model of heat and mass transfer of harmful impurities and heat in an industrial environment with active ventilation and sources of pollution and heat release, which allows one to take into account the turbulence of gas-air flows. The standard kepsilon turbulence model, adapted for welding shops equipped with stationary workstations with sources of pollution, took into account only the convective component of heat transfer, which is quite reasonable for large-volume rooms (with a low density of distribution of pollution sources), especially since the results of model calculations with taking into account only the convective component correlated well with the obtained experimental data.

However, for the purposes of this comprehensive study, when the work covers small confined spaces, where it is necessary to take into account bodies heated to a high temperature (during welding), which are next to each other as additional sources of heat release, it is no longer possible to neglect the radiation heat transfer.

Currently, a large number of various models have been created for calculating turbulent flows: Boussinesca, Spalart-Allmaras, large vortex method, Reynolds stress model, kepsilon and k-omega models, etc. They differ from each other in the complexity of the solution and the accuracy of the flow description. Since the direct calculation of the complete Navier-Stokes equations [5] for a three-dimensional turbulent flow requires significant computational resources, all the main applied models are based on one or another approximation. In addition, there is a difficulty in numerical solution methods associated with the need to use extremely fine grids when calculating the flow in a turbulent boundary layer, which leads to a violation of the stability of the calculation.

As a result of the review and analysis of existing models, it is possible to propose to use the k-epsilon turbulence model, which is most often used in solving practical problems and gives quite satisfactory results, to determine the fields of concentrations of harmful substances and parameters of the industrial microclimate in conditions of turbulence of air flows and take into account the convective and radiation components of heat exchange. for calculations of ventilation processes and processes of the spread of harmful substances and heat excess. For the implementation of the mathematical model, the most preferred software is ANSYS, which allows solving such complex problems [14].

The development of a ventilation system for a welding cabin is based on calculations of the required air changes for the design of its ventilation, which should take into account the technological parameters of the flux-cored wire welding process and an expanded range of harmful substances released into the working area (its toxicity).

The main disadvantages of the known methods of inventory of emissions of harmful substances of explosives, as well as methods for choosing ventilation equipment for premises, include the following:

- the methods are focused on aggregated (annual) emissions based on approximate specific emission indicators, and ventilation is calculated from the maximum one-time emissions during the most intense hour of work;

- the data bank on specific emission values for flux-cored wire welding InnershieldNR207 practically absent and needs experimental refinement; 
- calculations of the required air changes for the design of ventilation systems (general and emergency) of premises are usually carried out at the Maximum permissible concentrations of harmful substances in the air of the working area of the most toxic substance, referring it to one hour of work and not taking into account more toxic components, including the effects of the summation of harmful effects;

- when choosing the performance of the ventilation unit, they are often guided by the requirements of SNiP 2.04.05-91*(2000), determining the ventilation performance in terms of frequency, while not taking into account departmental standards (for example, VSN0189 ), where the calculation is made based on the hazardous emissions.

To reduce the content of harmful substances to the maximum permissible concentration, polluted air is removed from the production premises and diluted using mechanical supply and exhaust ventilation. The amount of air required for this (ventilation air exchange) is determined as the ratio of the specific emission of a harmful substance to its MPC and depends on the type and brand of welding material. The value of the ventilation air exchange to some extent can serve as a measure of the toxicity of the welding aerosol, and shows what air volumes are contaminated to the maximum permissible concentration when using certain brands of welding consumables. In domestic practice, the calculation of ventilation air exchange is carried out according to the leading toxic component of the welding aerosol.

However, to compare and classify electrodes according to the toxicity of the generated welding aerosol, it is necessary to take into account the summation effect, so the International Welding Institute proposed using an indicator of the toxicity of the welding aerosol, which is called the air exchange rate (IV in $\mathrm{m}^{3} / \mathrm{h}$ ), necessary to achieve the MPC of the welding aerosol, taking into account the toxicity its composition of components, and not the leading toxic component.

Thus, taking into account the most toxic of all chemical components of the substance and the effect of the summation of the harmful effects emitted by harmful substances when welding with flux-cored wire will make it possible to avoid errors in the calculations when determining the required air exchange and choosing the power of the power plant of the ventilation system of the cabin. Thus, the required air quality in the welder's working area can be achieved and safe working conditions for welders can be ensured in terms of the chemical factor and microclimate parameters, which is important in connection with the direction of this complex project.

However, ensuring safe working conditions for welders and the development of air protection systems for enclosed spaces of the working area is impossible without a calculated determination of the hazard or health risks. So, at present, there are many Russian and foreign models for assessing health risks for the population in general. However, most of the techniques are based on two approaches: MPC concept and methodology developed by USEPA (American Environmental Protection Agency). The Guidelines for assessing the risk to public health when exposed to chemicals that pollute the environment of the Russian Federation (Guideline R. 2.1.10.1920-04) [6] present the main provisions of the risk assessment methodology, in particular, the methods for calculating the risk at various exposures are considered in detail impurities. The methodology of B.A. Revich, [7] Doctor of Medical Sciences, member of the Presidium of the All-Russian Organization "Risk and Health", which is the basis for calculating health risks, involves environmental and epidemiological work. The method for assessing health risk by introducing the concept of "relative risk" was developed by R. Fletcher and described in his work [8]. The risk assessment method proposed in the works of A.V. Kiselev [8], Professor of the Department of Medical Ecology named after G.V. Khlopin State Educational Institution of Additional Professional Education "St. Petersburg Medical Academy of Postgraduate Education", is based on generally accepted regulatory and 
scientific-methodological documents, which set out the fundamental postulates of health risk assessment. It should be noted that S. M. Novikov, S. L. Avaliani, G. G. Onishchenko also had written a number of works on risk assessment. It can be concluded that their methods are based on the basic principles of risk calculation presented in the Guide [6]. To describe the relationship between the dose and the response to it in the works of P.A.Vaganov, two models are proposed: linear-quadratic and Weibull-Gnedenko model. Finally, the American health risk assessment methodology is proposed in the writings of Leon J. Warshaw. Over the past few decades, health risk assessment (HRA) became super popular in the USA. This assessment promotes awareness among American workers of the importance of health and management of the necessary actions to achieve this goal. It also prepares or replaces periodic health checks. In the article by N.I. Lukyanova and E.S. Popova in 2011, the possibility of assessing the health risk for the Frunzensky district of the city of St. Petersburg, experiencing significant air pollution of the atmosphere, is being investigated; the linear-quadratic model and the Weibull-Gnedenko model are used for the assessment.

In connection with the orientation of the complex project to assess the health risk of welders, it is necessary to consider the degree of knowledge of this problem in relation to the occupational pathologies of workers in welding production. Thus, the need to study complex and ambiguous working conditions of welders to assess their occupational diseases was already stated in the 1980s in the works of Deynega V.G., Prilutskij V.I. and Korenevskyv. At the same time Ryabova O.I., Davydova N.I., Kalashnikova A.A. in 1983, chronic manganotoxicosis of welders was first described and the development of a humoral immune response to antigens of the myelin sheath of nerve fibers was revealed, which can be used to clarify the severity of the investigated occupational disease of welders. Konstantinova T.N., Lakhman O.L., Katamanova E.V., Kartapoltseva N.V., Meshcheryagin V.A., Rusanova D.V. and Andreeva O.K. in 2009, have shown that cases of chronic manganese intoxication of the second and third stages are common among electric welders. In this case, the diagnosis was established on the basis of long-term work experience in contact with manganese, the level of which in the air of working rooms exceeded the MPC by 1.5 times. The article also notes some signs of the disease: a high content of manganese in the blood and urine, characteristic neurological symptoms in combination with psychopathology of the defective organic level and the presence of polyneuropathy of the extremities. In 2010, in the article by Zibarev E.V., Chashchin M.V., Nikonova S.M., Kusraev Z.S., Kuzmin A.V., Ellingsen D.G., Thomassen Y. [8], based on the biological monitoring data of electric welders, a reliable correlation was established between the concentration of manganese in whole blood and the concentration of manganese in the air of the working area. A significant decrease in the concentration of iron, cobalt and manganese in the urine was revealed in patients with a diagnosis of chronic manganese intoxication compared with the control group.

Medical studies of the conditions for the occurrence and course of professionally caused diseases of dusty pathology of the respiratory organs with the justification of the need to separate such diseases into a single group are set out in the works of Eselevich S.A. and Razumova V.V. in 2007. For the first time, the assessment of radiological changes in the lungs in modern forms of pneumoconiosis and hypersensitive pneumonitis, developed from exposure to welding aerosol in the works of T.B. Burmistrova, was carried out and Komarova T.A. in 2009. In the works of Shpagina L.A., Vlasenko M.V. and Bobrova S.V. in 2010, changes in the vascular-platelet hemostasis and the fibrinolysis system were revealed in persons in contact with highly fibrogenic dust, which makes it possible to clarify the mechanisms of implementation of the effect of industrial aerosol on the respiratory organs. Vlasenko M.V. and Bobrova S.V. in 2010, in their work, founded that the assessment of the state of various links of hemostasis in patients with dusty lung 
pathology, depending on the severity of respiratory failure, makes it possible to identify early changes indicating the presence of hypoxia. Dorn O.Yu., Peskov S.A., Poteryaeva E.L., Tsikalenko E.A., Maslennikov A.B., Smirnova E.L., Polyakov A.Ya. and Gerasimova E.The. in 2011 described the risk factors for the development of gastropathy in workers in dust-hazardous occupations. The results of assessing the health risk of workers employed in dust-hazardous production are given in the article by A.M. Oleshchenko, V.V. Zakharenkov, D.V. Surzhikov, V.V. Kislitsyn and Korsakova T.G. in 2016. The article presents the results of risk assessment: chronic intoxication; acute toxic effects; carcinogenic; development of occupational diseases of dust etiology.

The impact of thermal and chemical unfavorable factors was studied and presented in the works of Afanasyeva R.F., Bobrov A.F., Losik T.K., Suvorov V.G. in 2003 and Rembovsky V.R., Mogilenkova L.A. in 2004. So, in these works, regression equations are given to determine the criterion indicators of the optimal thermal state and the distribution of various cohorts (groups) of workers by classes of health status is made, which makes it possible to promptly screen and assess the structure of health status in the observed cohorts, can be used for forecasting and developing preventive measures at controlled enterprises. A little later, in 2008, Tkacheva T.A. and Karpukhina E.A. and Kayutina S.V. c investigated the possibility of the onset of adverse effects in workers in conditions of exceeding the maximum permissible concentration in the air of the working area, using the created database on the parameters of toxicometry of industrial substances. In addition, they proposed a modification of the boundaries of subclasses of harmful working conditions in terms of the frequency of exceeding the maximum permissible concentration for substances of general toxic type of action of 1-4 hazard classes. The working modes of electric welders in a heating microclimate were studied in the work of G.A. Sorokin and Frolova N.M. in 2010 year. The authors set out the results of the development of hygienically grounded time standards for establishing options for in-shift work and rest modes of electric welders working in various positions and with different visual voltage during electric welding of various products in a heating microclimate [21-23].

The need to develop concepts and approaches to assessing individual occupational risk is outlined in the works of S.L. Ustyantsev in 2006. General methodological approaches to assessing professional risk are presented in the work of S.F. Shayakhmetov. and Dyakovich M.P. in 2007. The relevance of the development and use of combined models for assessing occupational risk and hygienic justification is described in the works of A.V. Meltser and Kiseleva A.V. in 2009. At the same time, the authors believe that the methodology of occupational risk proposed by them will make it possible to predict the likelihood of occupational diseases and nonspecific diseases, to determine the length of service in workplaces and professions, to increase the role of preliminary and periodic medical examinations, thereby contributing to the solution of issues of health protection of workers. The issues of professional risk management taking into account the new documents are considered in the work published in 2011 by E.I. Denisov, L.V. Prokopenko, I.V. Stepanyan. and Chesalin P.B.. In addition, the authors point out that the introduction of the concepts of risk and its management in the Labor Code of the Russian Federation reflects a change in the forms of occupational health and safety. They proposed improving the management of professional risks by introducing a forecasting and causation block based on information technologies. The methodology for assessing and managing the risk to public health in the system of legislative regulation of sanitary and epidemiological welfare of the population of Russia is described in the article by S.V. Kuzmin, V.B. Gurvich, O.V. Dikonskaya, O.L. Malykh and Yarushina C.B.. In addition, the authors provide a scheme for assessing and managing professional risks. [24]

The need for urgent improvement of the regulatory and methodological base, as well as information support, guaranteeing a high-quality account of occupational cancer incidence 
in Russia is emphasized in the article by Ilnitsky A.P. and Solenova L.G. in 2017. The authors of the article show that an important role in solving this problem is played by the continuation of the sanitary and hygienic certification of carcinogenic organizations in the Russian Federation and the creation of the Federal register of persons who have/had industrial contact with carcinogenic factors in the form of a state automated information system.

\section{Conclusions}

Thus, at present there are general approaches and models for assessing the risk to public health in general, the mechanisms of the effect of dust particles on the development of occupational pathologies in welders, including toxic (manganese intoxication) and carcinogenic ones, have been studied in depth, a number of articles are devoted to the study of the effect of the thermal factor. chronic in nature. However, the studies are scattered, the combined effect of physical (thermal) and chemical (toxicants) factors is not taken into account $[17,18]$, based on the S. Arrhenius equation, illustrating an increase in the rate of chemical reactions with an increase in the temperature of the environment, which is especially important in closed conditions of the working area spaces. In addition, there is no comprehensive methodology for assessing health risks for workers in dust-hazardous industries and, in particular, for welders $[19,20]$. In this regard, as it seems to the authors of this study, the development of the above-mentioned comprehensive methodology for assessing the health risk of workers in dust-hazardous industries based on taking into account hazardous factors of physical and chemical nature is very promising in the near future.

\section{References}

1. Yu.I. Bulygin, D.A. Koronchik, A.N. Legkonogikh et al., IOP Conference Series: Earth and Environmental Science, 012015 (2017)

2. Yu.I. Bulygin, D.A. Koronchik, A.A. Abuzyarov, IOP Conference Series: Materials Science and Engineering, 012074 (2015)

3. O.V. Denisov, Yu.I. Bulygin, A.E. Ponomarev, et al., IOP Conference Series: Earth and Environmental Science, 012044 (2017)

4. Yu.I. Bulygin, M.G. Zharkova, L.N. Alekseenko, IOP Conference Series: Earth and Environmental Science, 012002 (2017)

5. M.G. Zharkova, S.I. Kolesnikov, 18th International Multidisciplinary Scientific GeoConferences SGEM 2018, Conference proceedings, 551-558 (2018)

6. E.S. Andreeva, E.O. Lazareva, I.N. Lipovitskaya, Vestnik of Moscow University. Series 5: Geography 2, 55-60 (2019)

7. E.S. Andreeva, P.V. Klimov, I.N. Lipovitskaya, S.S. Andreev, O.V. Denisov, International Multidisciplinary Scientific GeoConference SGEM 19-5.2, 115-122 (2019) doi: 10.5593/sgem2019/5.2/S20.015

8. S.S. Andreev, E.S. Popova, Bulletin of St. Petersburg University 7- 4, 145-150 (2015)

9. E.J.B. Van Etten, C.D. McCullough, M.A. Lund, Transactions of the Institutions of Mining and Metallurgy A(123-1), 9-19 (2014)

10. M.L. Blanchette, M.A Lund, Current Opinion in Environmental Sustainability, 28-34 (2016)

11. J. Morrison, Sustainable development (Profile Books, UK, 2002) 
12. V.M. Smolyaninov, T.V. Ovchinnikova, T.V. Ashikhmina, P.S. Kuprienko, Water and ecology: problems and solutions 2(78), 50-58 (2019)

13. I. Pasiecznik, K.P. Banaszkiewicz, J. Leoniewska-Gogola, Journal of Ecological Engineering 16(3), 124-129 (2015)

14. Y.I. Bulygin, E.V. Shchekina, D.S. Popov et al., AIP Conference Proceedings 2188(1), 050033 (2019) DOI: 10.1063/1.5138460

15. V.M. Grishagin, A.V. Filonov, S.V. Kiselev, IOP Conference Series: Materials Science and Engineering, 012010 (2016)

16. E.N. Korzhova, T.V. Stepanova, S. Lodousamba et al., Diagnostics of materials 81(7), 6-18 (2015)

17. K. Sriram, G.X. Lin, A.M. Jefferson et al., Toxicology 328, 168-78 (2015) doi: 10.1016/j.tox.2014.12.015

18. F. Golbabaei, H. Hassani, A. Ghahri et al., Int J. OccupHyg. 4(1), 6-9 (2015)

19. A. Karimi, J.H. Slukloei, S. Eslamizad, J OccupHyg Eng. 1(2), 47-56 (2014)

20. B. Meskhi, V. Bondarenko, I. Efremenko, V. Larionov, D. Rudoy, A. Olshevskaya, IOP Conf. Series: Materials Science and Engineering 1001, 012100 (2020) doi:10.1088/1757-899X/1001/1/012100

21. Y. Lachuga, B. Akhalaya, Y. Shogenov et al., IOP Conf. Series: Materials Science and Engineering 1001, 012121 (2020)doi:10.1088/1757-899X/1001/1/012121

22. B. Meskhi, V. Bondarenko, I. Efremenko et al., E3S Web of Conferences 217, 06012 (2020) https://doi.org/10.1051/e3sconf/202021706012

23. S. Antipov, I. Khozyaev, V. Panfilov, D. Rudoy, and S. Shakhov IOP Conf. Series: Materials Science and Engineering 1001, 012137 (2020) doi:10.1088/1757899X/1001/1/012137 